\title{
Fortalecer os pilares da sociedade democrática
}

\author{
José Marques de Melo
}

\section{SciELO Books / SciELO Livros / SciELO Libros}

MELO, JM. Cidadania glocal, identidade nordestina: ética da comunicação na era da internet [online]. Campina Grande: EDUEPB; Latus, 2011. 108 p. ISBN 978-85-63984-07-4. Available from

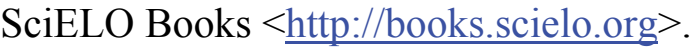

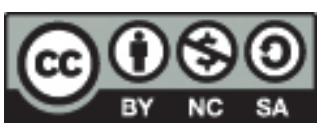

All the contents of this work, except where otherwise noted, is licensed under a Creative Commons Attribution-Non Commercial-ShareAlike 3.0 Unported.

Todo o conteúdo deste trabalho, exceto quando houver ressalva, é publicado sob a licença Creative Commons Atribuição Uso Não Comercial - Partilha nos Mesmos Termos 3.0 Não adaptada.

Todo el contenido de esta obra, excepto donde se indique lo contrario, está bajo licencia de la licencia Creative Commons Reconocimento-NoComercial-CompartirIgual 3.0 Unported. 


\section{Fortalecer os pilares da sociedade democrática ${ }^{9}$}

Agradeço, comovido, a homenagem que me presta a Universidade Federal da Paraíba, outorgando nesta solenidade o honroso título de Doutor Honoris Causa.

Quero expressar o meu reconhecimento particular aos professores doutores Moacir Barbosa e Wellington Pereira, que encabeçaram a iniciativa, respaldada pelo Departamento de Comunicação e acolhida pelo Conselho Universitário.

Confesso que fiquei duplamente sensibilizado pela generosidade dos colegas.

9 Discurso pronunciado em João Pessoa, em 2005, no ato de outorga do título de Doutor Honoris Causa pela Universidade Federal da Paraíba. 
Em primeiro lugar, por ser um nordestino, desterrado há 40 anos em terras paulistas, que merece o reconhecimento intelectual dos seus conterrâneos. Foi com o coração partido que, logo depois de diplomado em Jornalismo, embarquei, não num pau-de-arara, como o fizeram tantos nordestinos expulsos pela seca ou pela miséria, mas numa aeronove da Varig, acossado pelas perseguições políticas praticadas pelos novos donos do poder, os golpistas de 1964.

Em segundo lugar, por ser um jornalista que abriu o caminho da pesquisa acadêmica da área, enfrentando gregos e troianos, mas que hoje se considera gratificado pela legitimação e revitalização dos estudos jornalísticos em todo o país. Quando defendi a primeira tese de doutorado em Jornalismo na Universidade de São Paulo, nunca imaginei que 30 anos depois veríamos constituída uma Sociedade Brasileira de Pesquisadores em Jornalismo, integrada por mais de uma centena de participantes, a maioria com doutorado na área. Essa mesma entidade ensaia agora os primeiros passos para editar uma revista internacional, cuja proposta é a disseminação do conhecimento acumulado sobre o jornalismo brasileiro, junto às vanguardas acadêmica e profissional de outros países.

Esse conhecimento vem sendo produzido por duas centenas, ou mais, de universidades 
que, em todos os quadrantes do território nacional, mantêm programas de ensino na área, muitas delas também investindo na pesquisa.

Contudo, investir em pesquisa não pode significar o distanciamento e o alheamento da academia em relação aos problemas concretos que marcam a produção cotidiana das notícias nas redações. Esperam-se justamente dos estudiosos amparados pelas universidades as soluções para que os profissionais, as empresas e os cidadãos possam superar impasses históricos.

Vou focalizar uma dessas questões candentes: a leitura de jornais por parte da nossa população. Quando comparamos a situação do Brasil com outros países, percebemos um quadro vexatório. Nossos índices de leitura são ridículos. Para uma população de 180 milhões de habitantes somente dispomos de menos de 10 milhões de exemplares diários de jornais. Se somarmos a tiragem de todos os diários brasileiros, verificaremos estarrecidos que ela é inferior à tiragem isolada de qualquer um dos principais jornais da cidade de Tóquio num dia comum.

Circulando em camadas restritas da nossa sociedade, os jornais diários e as revistas semanais privilegiam conteúdos distanciados do cotidiano da população, agendando temas e 
problemas de interesse exclusivo das elites. A grande maioria do nosso povo só pode matar a sua fome de notícias através do radio e da televisão. E, dirigindo-se a audiências intelectualmente depauperadas, os veículos audiovisuais estão condenados a simplificar sua linguagem e aligeirar seu conteúdo. Do contrário, não poderão sobreviver como empresas. A questão que gostaria de propor aos meus colegas jornalistas, professores e estudantes de jornalismo, aqui presentes, é a seguinte: se ao grosso da população brasileira resta participar do banquete civilizatório através da mídia audiovisual, de que forma ela pode transformar suas rotinas profissionais no sentido de exercer

90 um papel educativo, contribuindo para elevar o nível intelectual dessas "multidões solitárias" como outrora as denominou o sociólogo norte-americano David Riesman?

Enquanto não lograrmos a universalização da educação básica de qualidade para toda a população nacional, formando assim contingentes de leitores críticos, permanecerá o dilema informacional daquelas maiorias de excluídos do saber que só podem recorrer aos veículos potencializadores de imagens e sons.

É justamente aí que reside um dos impasses colossais das nossas escolas de comunicação, particularmente dos seus cursos de jornalismo. Pois eles privilegiam de modo ostensivo 
programas de ensino ancorados exclusivamente no referencial da cultura erudita, desdenhando quando não desprezando o universo popular. A ênfase da produção de mensagens na maioria das nossas instituições permanece estacionária na mídia gutenbergiana, quando nada extrapolando para as formas de expressão escrita disseminadas pela internet.

Tenho feito essa observação contundente para os jovens que frequentam os meus seminários de pós-graduação, percebendo que eles abstraem a realidade em que irão atuar profissionalmente, talvez por influência de um sistema universitário elitista e excludente. Quero reiterá-la aqui, justamente porque nunca perdi minhas raízes culturais, tendo agora a oportunidade de resgatá-las e valorizá-las.

Gostaria de desafiar a nova geração dos estudiosos do jornalismo da nossa região, no sentido de buscar alternativas pedagógicas que correspondam às aspirações dos contingentes de famintos de cultura e de informação, nutrientes fundamentais para convertê-los em cidadãos ativos e participantes. Do contrário, eles permanecerão alvo fácil das manipulações dos populistas de todas as matizes hábeis no uso da mídia audiovisual.

Compete-nos a responsabilidade de repensar nossas estruturas de ensino, pesquisa e extensão, tornando o espaço universitário um 
instrumento da transformação social e da elevação do nível cognitivo daqueles que estão excluídos da sociedade de consumo. É claro que não estou pregando a omissão em relação à produção dos conhecimentos básicos que alavancam os segmentos das ciências aplicadas. Senão a universidade deixaria de ser uma instituição pautada pela excelência e pelo vanguardismo. O que ela não pode continuar a ser é uma torre de marfim.

Somente o diálogo construtivo e permanente com a sociedade pode conduzir a universidade, em geral, e os cursos de comunicação, em particular, a novos patamares de 92 organização acadêmica, evitando inclusive o perigo letal da sua rendição aos interesses corporativos.

Vejo com muita preocupação a tendência manifestada em instituições de todo o país, distanciando os programas de graduação da sua responsabilidade de formar profissionais críticos e competentes para atuação imediata no mercado de trabalho, optando por uma estratégia aparentemente sedutora no sentido de arregimentar novas vocações para a pesquisa acadêmica. Não é raro defrontar-me com jovens estudantes de jornalismo que, sem terem participado de projetos consistentes de iniciação científica, já estão preocupados em conquistar vagas na pós-graduação. Entendo 
que o estímulo à pesquisa é importante para formar profissionais qualificados, mas não podemos transformar a pesquisa num fim em si mesmo, desvinculada de suas aplicações no cotidiano dos jornalistas que vão atuar nas empresas midiáticas.

Finalmente, gostaria de compartilhar com os meus colegas desta universidade, uma preocupação que me angustia ultimamente. Trata-se da preservação de uma das grandes conquistas da tenra democracia brasileira. Refiro-me ao instituto da liberdade de expressão e pensamento, fundamental para o exercício do jornalismo responsável. A Constituição de 1988 não apenas institucionalizou a sua concepção, mas ousou até mesmo incluir um artigo inspirado na primeira emenda da carta constitucional norte-americana, que veda aos agentes do poder público criar leis destinadas a restringir o direito dos cidadãos a informar e ser informados, bem como a expressar suas opiniões.

Foi graças ao ambiente de liberdade desfrutado no período pós-autoritário que o Brasil pode fortalecer as instituições democráticas. A mídia tem tido papel decisivo nesse processo, investigando as mazelas da sociedade e denunciando publicamente os desvios praticados por pessoas ou entidades. Essa transparência política tem atuado como uma espécie 
de freio para os agentes públicos e ao mesmo tempo como mecanismo punitivo para aqueles que praticam ações delituosas.

Temos presenciado, contudo, tentativas esboçadas por agentes do poder executivo ou do judiciário no sentido de minar o edifício que sustenta a liberdade de imprensa. Artifícios ostensivos ou dissimulados começam a despontar em cadeia, resultando em atos que restringem ou inibem o desempenho profissional dos jornalistas. Se não houver uma constante vigilância da sociedade, corremos o perigo de retrocesso.

Cada segmento deve fazer a sua parte para 94 prevenir as rachaduras do edifício: empresas midiáticas, sindicatos profissionais e a sociedade civil. O que pode fazer a universidade? Antes de tudo, sedimentar melhor a formação ética dos futuros jornalistas, bem como reforçar o conhecimento dos limites impostos pela lei para o exercício profissional. Este último aspecto tem sido negligenciado, contribuindo para criar na nova geração o sentimento de impunidade e descaso em relação aos preceitos legais por absoluta ignorância em relação a eles.

Enfim, poderíamos continuar refletindo sobre outros aspectos candentes da atividade jornalística neste novo milênio: globalização, regionalização, identidade cultural, 
pluralismo opinativo, agenda pública, espiral do silêncio etc, etc.

Confesso, porém, que seria mais confortável dar continuidade a essas reflexões, não através do monólogo, inevitável em solenidades dessa natureza, mas em situações dialógicas, onde pudéssemos intercambiar pontos de vista, contrapor ideias ou refutar argumentos.

Creio que não faltarão oportunidades para isso, agora que começo, com muita honra, a fazer parte do corpo docente desta universidade.

Muito obrigado a todos. 